\title{
An Instructional Method Suggestion: Conveying Stories through Origami (Storigami)
}

\author{
Aysegul Oguz \\ Correspondence: Asst. Prof. Dr. Aysegul Oguz, Department of Primary Education, Faculty of Education, Recep Tayyip \\ Erdogan University, Rize, Turkey.
}

Received: March 28, 2016 Accepted: April 19, $2016 \quad$ Online Published: April 24, 2016

doi:10.11114/jets.v4i8.1573

URL: http://dx.doi.org/10.11114/jets.v4i8.1573

\begin{abstract}
The purpose of this study was to elucidate how to convey stories through origami and suggest its use in education with the help of pre-service elementary teachers' opinions. The participants of the study were 103 elementary teacher candidates from a state university in the 2014-2015 academic year. In this qualitative study, the data were collected through semi-structured interviews and analyzed employing content and descriptive analyses. During the content analysis, the data were coded, organized under themes, and represented in frequency and percentage tables. In the descriptive analysis, the opinions of teacher candidates were interpreted using direct quotes. The results indicated that conveying stories through origami is a viable instructional method for many courses and topics.
\end{abstract}

Keywords: origami, storigami, stories through origami, instructional methods, teacher candidate

\section{Introduction}

Origami is known as the Japanese art of paper folding. The word origami stems from the combination of the Japanese words Ori (i.e., folding) and Kami (i.e., paper) (Katz, 2015). TDK (2015) defines origami as "a paper folding art to generate life-like or inanimate figures that often does not involve cutting or use of adhesives". Many instructional objectives can be attained through the use of origami. "Origami is an activity-centered method that is related to modern learning methods including learning by doing, collaborative learning, creative learning, active learning, project-based learning, and brain-based learning. Research on origami has shown that origami can contribute to the development of motor, intellectual, and creativity skills of pre-school- and elementary-school-age children" (Tugrul \& Kavici, 2002, p.14-15).

Origami has been used as an effective teaching and learning tool, especially in mathematics and geometry. Research shows that origami can be used as an effective tool in the courses in education (Arici \& Aslan Tutak, 2015; Canadas, Molina, Gallardo, Martinez-Santaolalla, \& Penas, 2010; Zarei \& Branch, 2015). Another use is story creation activities; however, telling stories through origami is a rarely-utilized practice in education. In his study, Mastin (2007) named the practice of telling stories through origami as 'storigami' and stated that this method has many educational advantages including strengthening memory, improving fine motor muscle coordination, enhancing left and right brain accordance, and fostering creativity.

The extant literature provides various ways to use origami as an effective learning tool. Johnson (1999) suggested that paper folding can be used to make students interested in mathematics. Wares (2011), in his/her study, integrated origami and geometrical concepts. Cakmak, Isıkal and Koc (2014) maintained that origami had a positive effect on spatial abilities of elementary school students. Similarly, Boakes (2008) found that origami helped students in developing spatial skills, and she emphasized its importance in geometry teaching. Pope (2002) stated that origami was effective in geometry teaching. Arslan (2012) stated that origami would be a feasible and beneficial tool in pre-service teacher education. Chen (2006) suggested that origami could help in teaching mathematics to hearing-impaired and deaf students. Ishihara (2014) maintained that crystal and molecule shapes represented through origami figures were not only three-dimensional structures but also learning materials that could be used in science classrooms. Currier (2015) stated that origami could benefit conceptual learning, vocabulary building, and problem-solving. Hence, the literature supports origami's importance and effectiveness as a teaching and learning tool. Through this study, I suggest that the storigami method that combines origami and storytelling; and it can be utilized in numerous teaching and learning situations. 


\section{Method}

The purpose of this study was to elucidate how to convey stories through origami and suggest its use in education with the help of pre-service elementary teachers' opinions. The participants of the study were 103 elementary teacher candidates from a state university in 2014-2015 academic year. Participation in the study was voluntary. The researcher, first, introduced the storigami method to the participants by telling an example story through origami. Then, the participants followed the researcher's lead and did the same actions as she re-told the story. After that, the participants' opinions were investigated using an interview form including the following questions and instructions: "In what courses conveying stories through origami (i.e., storigami), can be used, and how can a teacher use it? Exemplify the use of the storigami method by adopting it in an elementary-school-level topic. Please provide a detailed answer by stating learning objectives." In this qualitative study, the data were analyzed employing content analysis and descriptive analysis. In accordance with Yildirim and Simsek (2006, p. 228), data analysis was conducted in four steps: (a) coding, (b) establishing themes, (c) organizing codes and themes, and (d) defining and interpreting findings. In content analysis, the codes were organized under themes, and then represented in frequency and percentage tables. In the descriptive analysis, the opinions of the teacher candidates were interpreted and direct quotes were used to support interpretations.

The Example Story:

The bald guy has received a perfect score report this semester. His mother asks him what he wants as a reward. The bald guy answers that he wants to go shopping. And, the mother and son go to a shopping mall. (From this point forward, each object mentioned in the story is depicted through origami.) They purchase a sweater, a pair of boots, and a pair of shoes that the bald guy chooses from the display. They also get a pair of cowboy pants following the recent trends. Feeling hungry, they enter a restaurant and have a table for two. The bald guy's mother loves the food, calls for the waiter and asks "Could you tell me the name of this lovely place?" The waiter replies "It is the Star restaurant, madam." On the way home, they visit a park and take a gondola to relax. When they finally reach home, the bald guy's mother looks in her purse for keys. She opens the house's door and they go in.

In the following sections, instructions to create origami figures from the story are given. Fold a standard paper diagonally to form a square, cut off the extra part. Alternatively, you can also start with a square-shaped paper. The process of telling the story is also shown in Appendix through photographs.

\section{Findings}

The teacher candidates' answers to the question "In what courses can conveying stories through origami,(i.e., storigami), be used?" are listed in Table 1.

Table 1. In what courses can conveying stories through origami be used?

\begin{tabular}{llll}
\hline Course Group & Course & Frequency (f) & Percentage (\%) \\
\hline \multirow{2}{*}{ Quantitative } & Mathematics & 52 & 50.49 \\
& Geometry & 11 & 10.68 \\
& Science and Technology & 3 & 2.91 \\
\hline \multirow{4}{*}{ Verbal } & Turkish (Native Lang.) & 43 & 41.75 \\
& Life Science & 23 & 22.33 \\
& English (Foreign Lang.) & 4 & 3.88 \\
& Elementary Reading and Writing & 2 & 1.94 \\
\hline \multirow{2}{*}{ Fine Arts } & Geography & 2 & 1.94 \\
& Social Studies & 1 & 0.97 \\
\hline All courses & Visual Arts & 5 & 4.85 \\
\hline
\end{tabular}

The participants first answered the question: "In what courses can conveying stories through origami, (i.e., storigami), be used?" Some participants named more than one lesson in their answers. As seen in Table 1, courses fall into four themes titled quantitative, verbal, fine arts, and all courses. In the quantitative theme, mathematics was the most frequently mentioned course, followed by geometry, and science and technology. In the verbal theme, the majority of the participants referred to Turkish. Turkish was followed by life science, English, elementary reading and writing, geography, and social studies, respectively. As to arts use, the participants stated visual arts and music courses. Finally, eight of the participants claimed that storigami can be used in all kinds of courses. Overall, mathematics, Turkish, and life science were the most frequently referred courses. On the other hand, social science was the least referenced course with only one participant mentioning its name.

Considering the study context, the high frequency of mathematics use was an expected result because one generates multiple geometrical shapes and reference lines during the origami-making process. Storigami requires an effective use 
of language skills; therefore, Turkish being the second most frequent answer was also expected. The participants' fequent mention of life science course was not expected, yet it might be due to the course's strong connection to daily life events.

Storigami itself is a good way to catch elementary students' attention. Thus, teachers can embed storigami activities in their lessons to catch and sustain their students' attention. As storigami pleases both visual and auditory senses, it might likely to be more appealing and effective than telling stories alone.

How can a teacher use storigami in a lesson? Answering the second question, the teacher candidates shared their ideas of how storigami can be used in a lesson. The ideas were provided in the following paragraphs using direct quotes. The participant names were coded in P\# formats (e.g., P1, P2, etc.).

P6: "Each time one folds a paper during origami making, a different geometric shape is generated. Folding in half results in two equal pieces, so children observe equality. In the first stage of elementary education, shapes and their sizes can be taught this way." By these statements, the participant emphasizes that mathematical concepts such as equivalence, shapes, and sizes can be learned through storigami. P25 points out that storigami can be a useful tool to demonstrate geometrical shapes, size comparison, side length, and proportions in the following statements: "Origami can be used in math lesson to show geometrical shapes. If we adapt this; when teaching triangles, squares, and rectangles, first a square can be created; then a triangle can be created by merging its diagonal corners; and as we proceed the paper area becomes smaller. New squares, triangles, and rectangles can be formed despite the shrinking paper. In this way, geometrical shapes are introduced, and at the same time side lengths are taught by concrete examples." In a similar manner to $\mathbf{P 2 5}, \mathbf{P 6 0}$ related storigami to geometry teaching with statements such as: "What is the shape of the paper we hold?: a rectangle. What shape results if we meet a corner with a diagonal side and remove the extra part below?: triangle. What happens if we unfold it?: square. By activities like this, we can create student interest in geometrical shapes and increase students' interest in mathematics." By saying that, $\mathbf{P 6 0}$ also pointed to the interest gathering aspect of storigami.

P36: "The bald guy goes shopping with his mother. He buys boots for 5 liras. He then, buys shoes for 3 liras. Later, he sees a sweater for half of the money he has spent so far and buys it too. He pays twice as much as what he had paid for the sweater to buy pants. In the restaurant, his mother pays the bill with 2 liras less than the pants' price. Then, they take a gondola ride and pays half as much as the restaurant bill. I manipulated the story to include situations that require basic calculation tasks. This gains children's attention and also develops their calculation skills. In addition, without realizing it, they do mental calculations."

P1 shared a practical use of storigami in Turkish lesson with following statements, "It is important to present visuals to pupils in elementary reading and writing lessons. The figures formed during storytelling can also be used as visuals that get pupils to know the initials of the figures' names." Here, P1 emphasized the importance of visuals in elementary reading and writing instruction and suggested that shapes generated during storigami can be a means to introduce the initial letters of their names. K8 mentioned storigami's depictive functions for Turkish lessons with following expressions "I can use an origami generated through storytelling to teach depiction. I will use this story and increase the amount of depiction in it. So, students get an idea of story generation through depiction."

P11 implied that storigami can be used to teach adjectives in Turkish lessons by saying "I can utilize it in Turkish lessons. In the beginning of the story, our paper was in the shape of a sweater. By naming the sweater's color, one can teach colors - yellow sweater, red sweater etc., in this way, one can teach adjectives as well. Other shapes can be shown to teach the defining features of each." Similarly, P52 points at the use of adjectives by stating "We can adapt the origami shapes created to teach adjectives in Turkish lessons. We can emphasize the pants figure by saying 'Ali saw yellow pants', and paint the figure in yellow. Then, we can say 'He bought beautiful shoes' and stress the adjective beautiful." P17, on the other hand, it suggests using storigami to teach concepts and enhance learning in English lessons with following statements "I would like to apply this [storigami] method to the English lesson. I present the main concepts in English. Since the concepts are told through stories, it promotes learning retention for children."

The participants mentioned storigami's effectiveness and educational functions as well as its entertaining features. Their statements indicated that they focus on the task and that they acknowledge storigami as an instructional tool. They also highlighted that storigami can be a useful instructional tool for some hard-to-teach topics.

Elementary school students may have difficulty in naming concepts they actually know. For instance, students may use different words with similar meanings in daily speech, yet do not realize the words are synonyms. Likewise, students may confuse word types such as antonyms, synonyms, adjectives, and pronouns. Not all methods are suitable for all lessons. Considering its strong attention-gathering potential, teachers can use storigami to teach complex topics. One storigami activity can be used in multiple courses across a curriculum, which makes it a versatile method that is adaptable to a wide range of topics. 
Another question the participants answered was about the objectives that can be met by employing storigami in teaching. Their opinions were analyzed using content analysis and the results are presented in Table 2 showing frequencies and percentages. Details regarding the participant opinions and direct quotes are provided after the table.

Table 2. What objectives can be met by employing storigami?

\begin{tabular}{|c|c|c|c|}
\hline Theme & Code & $\begin{array}{l}\text { Frequency } \\
\text { (f) }\end{array}$ & Percentage $(\%)$ \\
\hline \multirow[t]{4}{*}{ Language Skills } & Making comments & 17 & 16.50 \\
\hline & Effective use of native language & 14 & 13.59 \\
\hline & Listening & 12 & 11.65 \\
\hline & Establishing communication & 11 & 10.68 \\
\hline \multirow[t]{7}{*}{ Study motivation } & Gathering attention & 39 & 37.86 \\
\hline & Arousing curiosity & 32 & 31.07 \\
\hline & Increasing attention & 28 & 27.18 \\
\hline & Active engagement & 15 & 14.56 \\
\hline & Positive attitudes towards lesson & 9 & 8.74 \\
\hline & Enjoying the lesson & 7 & 6.80 \\
\hline & Growing liking for the teacher & 3 & 2.91 \\
\hline \multirow{10}{*}{ Instructional processes } & Learning retention & 64 & 62.14 \\
\hline & Conceptual learning & 38 & 36.89 \\
\hline & Learning through fun & 37 & 35.92 \\
\hline & Audiovisually supported learning & 28 & 27.18 \\
\hline & Providing concrete examples & 27 & 26.21 \\
\hline & Learning by doing & 18 & 17.48 \\
\hline & Collaborative learning & 13 & 12.62 \\
\hline & Systematic learning & 10 & 9.71 \\
\hline & Developing observation skills & 10 & 9.71 \\
\hline & Increasing success & 2 & 1.94 \\
\hline \multirow[t]{5}{*}{ Cognitive development } & Spatial Skills & 19 & 18.45 \\
\hline & Attaining ecological awareness & 16 & 15.53 \\
\hline & Grasping easily & 12 & 11.65 \\
\hline & Developing an aesthetic sense & 2 & 1.94 \\
\hline & Acquiring a different point of views & 1 & 0.97 \\
\hline \multirow[t]{6}{*}{ Emotional development } & Self-confidence & 16 & 15.53 \\
\hline & Helping each other & 12 & 11.65 \\
\hline & Affective development & 3 & 2.91 \\
\hline & Emotion transfer & 3 & 2.91 \\
\hline & Patience & 3 & 2.91 \\
\hline & Quality time & 1 & 0.97 \\
\hline \multirow[t]{4}{*}{ Social skills } & Better self-expression & 4 & 3.88 \\
\hline & Interaction & 2 & 1.94 \\
\hline & Socialization & 1 & 0.97 \\
\hline & Leadership skills & 1 & 0.97 \\
\hline Psychomotor skills & Developing handicrafts & 63 & 61.17 \\
\hline \multirow[t]{7}{*}{ Cognitive skills } & Developing creative thinking skills & 36 & 34.95 \\
\hline & Fostering imagination & 32 & 31.07 \\
\hline & Developing visual intelligence & 18 & 17.48 \\
\hline & Connecting to daily life & 17 & 16.50 \\
\hline & Multidimensional thinking & 7 & 6.80 \\
\hline & Developing thinking skills & 3 & 2.91 \\
\hline & Realizing personal skills & 3 & 2.91 \\
\hline
\end{tabular}

Table 2 reflects the participants' opinions about the learning objectives that can be met through storigami and it consists of eight themes, namely language skills, study motivation, instructional processes, cognitive development, emotional development, social skills, psychomotor skills, and cognitive skills. The most frequent codes were learning retention, developing handicrafts, gathering attention, learning concepts, learning with fun, developing creative thinking skills, 
fostering imagination, arousing curiosity, increasing attention, audiovisual learning, providing concerete examples, learning by doing, developing visual intelligence, making comments, connecting to daily life, attaining ecological awareness, and developing self-confidence. In the following section, the participant opinions were provided with direct quotes.

P7 maintained that the achievements of storigami include learning retention, self-confidence, attention, helping behavior, and socialization by saying that "Learning retention increases due to learning by seeing. Realizing being able to accomplish things by oneself, a child develops self-confidence. Since the child follows the teacher, the sense of attention develops. [The child] Asks a friend for help on things he cannot do. The sense of helping one another develops, and he builds rapport with his friends at the same time." P66 stressed helping behavior with following statements: "When telling a story, we ask children to watch carefully. Then, we try to do it together. While doing, we instruct them 'please help one another'. With this method, children improve attention. By helping a friend, some self-centered children with undeveloped helping behavior, grow to develop a sense of helping. It [storigami] develops handicrafts. Children develop self-confidence as they create a product."

P11 The statements that follow mention storigami's relationship to attention increase, listening skills, and the creation of mental imagery in: "By utilizing this [storigami], the teacher gets children's attention and this develops their listening skills. Some students may have problems in creating mental imagery while reading. Storytelling in this way allows them to comprehend better." P16 also referred to increased listening and psychomotor skills by saying "During this activity, students will learn to listen to something with curiousity and patience. If students learn and practise this origami activity, they will also develop psychomotor skills." As storigami requires the active participation of the recipients, it is likely to promote the development of the skills that the teacher candidates suggested.

The box shape formed when the sample story concludes can be used as a waste bin. P36 connected this shape to environmental awareness in the following statements "They [students] can also use the box shape as a waste bin or other tool. This way, children do not waste but learn to save resources." P51 and $\mathbf{P 9 5}$ emphasized storigami's daily life relation with the following statements:

P51: "I make origami to introduce materials that are available in daily life and the environment."

P95: "They [students] study and participate in the lesson with great joy. Meanwhile, they think that the geometrical shapes seen in this game actually happen to be in virtually everything they use on a daily basis."

P58 proposed that storigami may have students experience quality time along with other benefits in the following statements: "It [storigami] fosters creative thinking. [Students] spend quality time, enjoy the lesson, and happily leave the classroom learning something." According Glasser (1998) all human beings have five basic needs: love, power, freedom, fun, and survival. These are built into our genetic structure, and from birth we must devote all our behavior to attempt to satisfy them. Quality, therefore, is anything we experience that is consistently satisfying to one or more of these basic needs (Glasser, 1998). Thus, we can claim that storigami increases the quality of the learning experience by bringing up enjoyment.

P59 mentioned various outcomes related to storigami methods in the following statements: "[Students] recognize three-dimensions, learn to explore, develop creativity and imagination, and are encouraged to listen."

P60 suggested that storigami can serve as an assistive technology for hearing-impaired students by saying that: "It [storigami] makes learning easier for students with hearing problems by adding visual objects and engages students by freeing the lesson from monotonicity." In other words, storigami could alleviate the adverse effects of some individual problems such as impaired hearing.

P61 claimed that the use of storigami may increase students' awareness of multipurpose materials in the statements that follow: "It shows students that numerous figures can be created using one material." The learning objective mentioned here is likely result in important outcomes since this activity can encourage individuals to improve available opportunities, conduct research, consider alternatives, and imagine. It can also trigger students' interest in creating new objects. Storigami makes creating new objects and ideas seem more feasible in students' eyes.

P62 and P71 maintained that since story and paper folding connected to each other in the storigami method, students can recall the figures by utilizing the story, or vice versa. They express this opinion in the following statements:

P62: "Since it [storigami] goes step by step, [a student] can remember a story from the order of origami figures even if he forgets the order of events, or remember the figures from the story even if he forgets the origami figures."

P71: "Due to concreteness, it gets easier to understand. Since it follows a specific organization and order, mental realization happens and comprehension becomes easier, observation skills develop." Therefore, it can be said that storigami generates memory cues. In a similar manner to P62 and P71, P68 emphasized the step by step nature of 
storigami. P68 also stated that storigami gets students curious about the next step and that it fosters creativity, increases attention, develops handicraft skills, teaches concepts, develops a sense of fun, and helps to increase ecological awareness development by saying "[Storigami] is a study that is creative, attention-piquing, getting one curious about the next step, teaching concepts by enhancing handicrafts. Children get happy when doing this, because of the end product; using this [the box figure] as a waste box, [children] both contribute to classroom cleanness and [prevent the [in-class] noise caused due to pencil sharpening excuses, contribute to environmental conscious.

With the statement "Seeing his skill development, a child tries to generate new figures, so his creativity and imagination are enhanced" P72 claimed that realizing improvements in one's skills may become a source of motivation to try new figures, and, as a result, creativity and imagination may be improved as well. P82's opinions regarding storigami's connection to learning with fun, observation skills, tracking, and self-confidence were apparent in the following statements: "[Storigami] brings fun to the topics that children find boring. Students' observation and tracking skills develop. It helps children to switch from a 'I can't do it, I don't understand' mindset to a 'I understand, I can do it, too' mindset. Finally, P102 suggested that storigami can be used to develop positive attitudes towards learning in the following statement: "[A student] starts expressing a positive attitude towards a course he was prejudicial to, like mathematics."

\section{Conclusion and Recommendations}

The preservice teachers who participated in this study stated that storigami can be used as a learning tool in many elementary-level classes such as mathematics, geometry, Turkish, and life sciences. They also mentioned that storigami could have positive effects on language skills, social skills, sensory skills, psychomotor skills, cognitive development, instructional processes, and students' motivation to learn. The participants maintained that storigami could also be used for a variety of educational purposes including improving retention, developing kinesthetic skills, gathering attention, supporting conceptual learning, making learning fun, developing creative thinking skills and imagination, triggering curiosity, supporting audio-visual learning, providing concrete examples, promoting spatial skills, supporting learning by doing, connecting to daily life, attaining environmental awareness, achieving self-confidence, and teaching to make constructive comments. Taken together, these opinions indicate the potential of storigami as an effective teaching and learning tool.

After a storigami activity, teachers can increase the effectiveness of it by showing students how to convey that same story. In the process, students may work in small peer groups, so that they interact with and help each other. Storigami activities can be applied to diverse topics. Storigami's practical application and requirement of inexpensive and accessible materials make it an advantageous instructional method. To foster ecological awareness, storigami materials can be chosen from old newspapers, magazines, and other sources of waste paper. Unlike some common classroom activities such as potato printing, storigami does not create unnecessary waste. In addition, its products are reusable in another activity or for another purpose. For example, students can use the shape generated in our sample story as a waste box. The durability of instructional materials is also of importance. Paper is a relatively durable material that can be used multiple times without serious deformation. Once a paper has been used in a storigami activity, the lines remaining on it can provide hints for students to recall how to do the activity. As the method does not require much alteration of the physical learning environment, the teacher can conveniently use storigami. Teachers hesitant to use storigami can examine the example provided here and decide whether they can employ storigami in their own lessons. Transporting and storing an origami product carry as much importance as the product itself. As storigami products do not occupy much space, they can easily be placed in student portfolio folders. This study investigated preservice teachers' opinions about the educational use of storigami and concludes that storigami methods can be used to achieve various educational objectives.

\section{References}

Arici, S., \& Aslan, T. F. (2015). The effect of origami-based instruction on spatial visualization, geometry achievement, and geometric reasoning, International Journal of Science and Mathematics Education, 13(1), 179-200. http://dx.doi.org/10.1007/s10763-013-9487-8

Arslan, O. (2012). Investigating beliefs and perceived self-efficacy beliefs of prospective elementary mathematics teachers towards using origami in mathematics education, Master Thesis, Middle East Technical University, Ankara.

Boakes, N. (2008). Origami-mathematics lessons: Paper folding as a teaching tool. Mathitudes, 1(1), 1-9.

Cakmak, S., Isiksal, M., \& Koc, Y. (2014). Investigating effect of origami-based instruction on elementary students' spatial skills and perceptions, The Journal of Educational Research, 107(1), 59-68, http://dx.doi.org/10.1080/00220671.2012.753861 
Canadas, M., Molina, M., Gallardo, S., Martinez-Santaolalla, M., \& Penas, M. (2010). Let's teach geometry, Mathematics Teaching, 218, 32-37.

Chen, K. (2006). Math in motion: Origami math for students who are deaf and hard of hearing, Journal of Deaf Studies and Deaf Education, 11(2), 262-266. http://dx.doi.org/10.1093/deafed/enj019

Currier, S. C. (2015). Unfolding a problem, Teaching Children Mathematics, $21(8)$, $476-482$. http://dx.doi.org/10.5951/teacchilmath.21.8.0476

Glasser, W. (1998). The quality school teacher, Harper Perennial.

Ishihara, S. (2014). Science origami, an effective teaching sid on dcience, Proceedings of the 12th Asia Pacific Physics Conference JPS Conf. Proc., 1, 017024.

Johnson, D. (1999). Paper folding for the mathematics class. Reston, VA: National Council of Teachers of Mathematics.

Katz, R. (2015). http://www.origamiwithrachelkatz.com/origami/origami.php, Date of Access: 22.12.2015 10.48

Mastin, M. (2007). Storytelling + origani = Storigami mathematics, Teaching Children Mathematics, 14(4), $206-212$.

Pope, S. (Ed.) Proceedings of the British Society for Research into Learning Mathematics. 22(3) November 2002.

TDK(2015),http://www.tdk.gov.tr/index.php?option=com_bts\&arama=kelime\&guid=TDK.GTS.56769beee4c4c5.2835 3494, Date of Access: 20.12.2015, 14.20.

Tugrul, B., \& Kavici, M. (2002). Kâğıt katlama sanatı origami ve öğrenme (Art of Paper Folding Origami and Learning), Pamukkale University Journal of Education, 1(11), 1-17.

Wares, A. (2011) Using origami boxes to explore concepts of geometry and calculus, International Journal of Mathematical Education in Science and Technology, 42(2), 264-272. http://dx.doi.org/10.1080/0020739X.2010.519797

Yildirim, A., \& Simsek, H. (2006). Sosyal bilimlerde nitel araştırma yöntemleri. (Qualitative research methods in social sciences). Ankara: Seckin Publishing.

Zarei, A., \& Branch, K. (2015). The role of teaching based on art therapy with origami method in the decrease of ultra-active pre-elementary school children's impulsive disorder of kermanshah township (in rotational disobedience and behavior disorder parameters). Journal of Educational \& Instructional Studies in the World, 5(1), 56-62.

\section{Appendix. Conveying a story through origami}

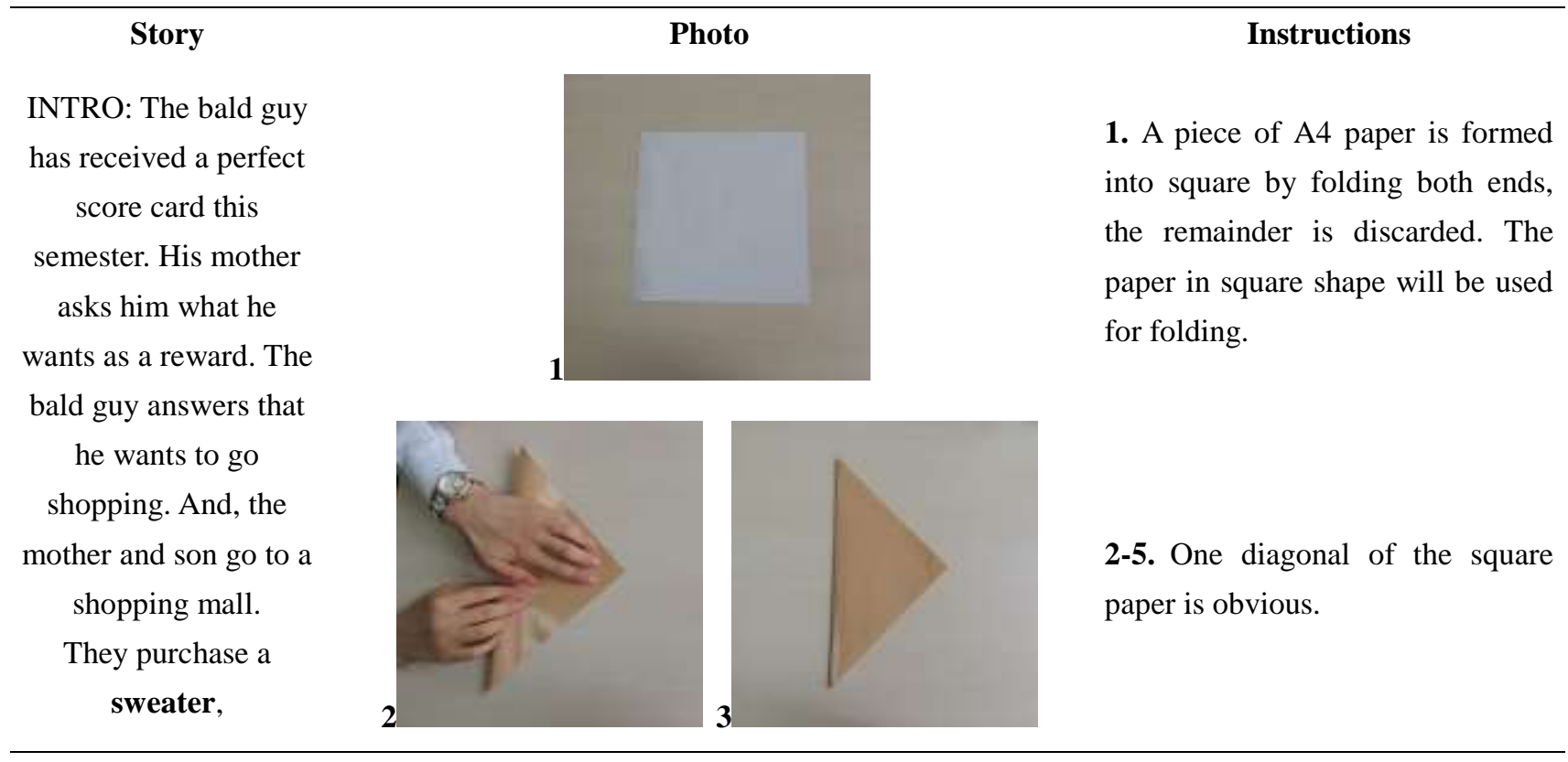



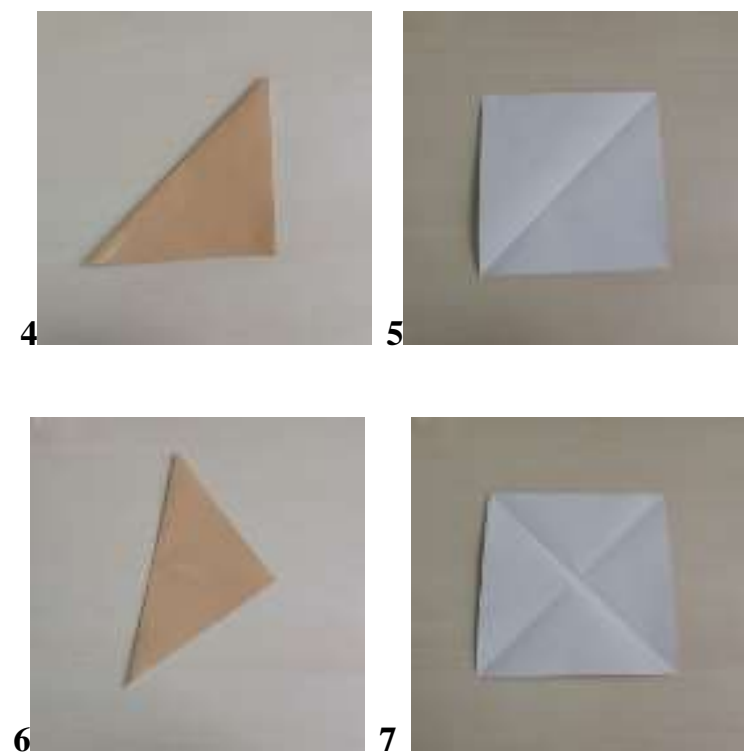

6-7. To clarify the other diagonal, folding is done by holding the other two corners of the square paper, and the paper is opened again. It is done to make the diagonals clear because all folding will be made on these lines formed.

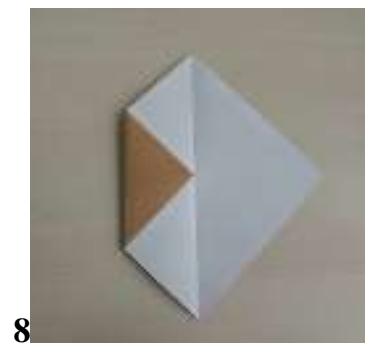

8. One corner of the square paper is held and folded by combining with the middle point.

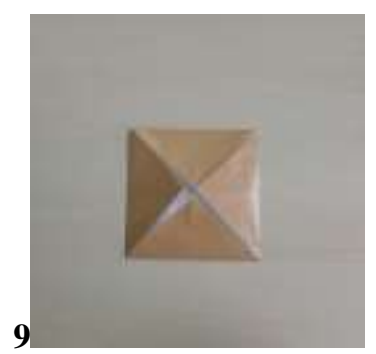

9. Every corner of the frame is combined in the mid-point in this way as if folding an envelope. It is very important to make folding clear and symmetrical for proper forms.

10. After the four corners of the square are combined in the mid-point, the square is inverted.

11. The same process is performed for this surface. 


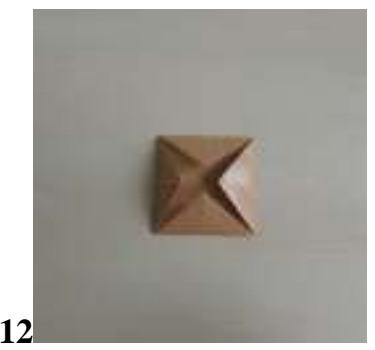

12. Every corner of the square is joined at the mid-point.

13. The square is inverted once again.

$14,15,16,17$. The same process is performed for this surface. Then, the square paper is reversed.

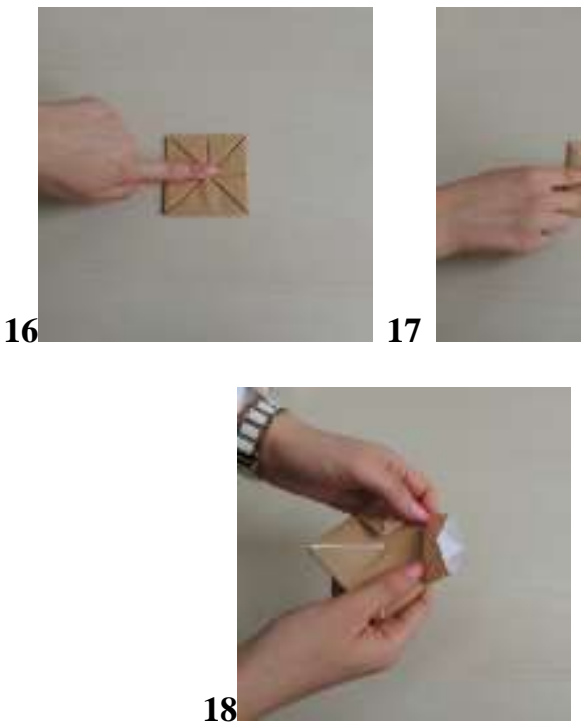

18. There are four equal squares on the paper surface. Each square consists of two identical triangles.

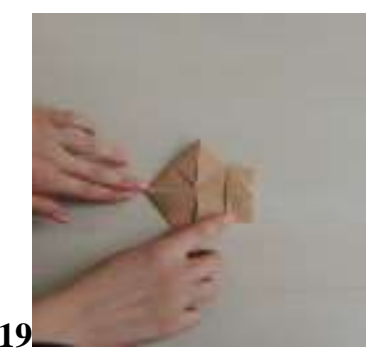

19. The corner of each square in contact with the center is folded by opening two triangle pieces. 
a pair of boots

and a pair of shoes that the bald guy chooses from the display.

They also get a pair of fashionable cowboy pants.

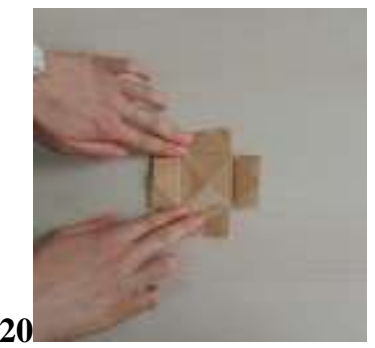

20. A form similar to "plus" sign by opening each square in this way.
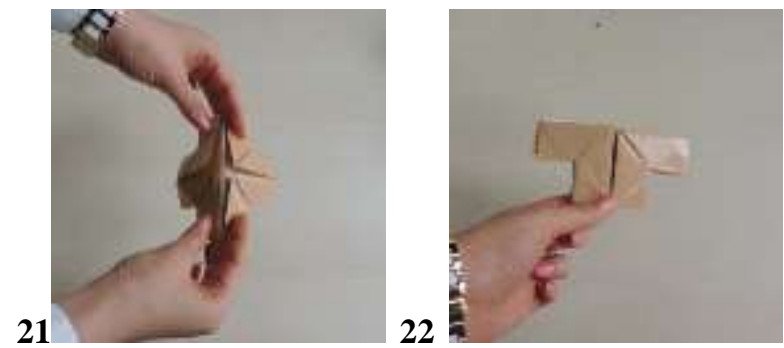

21,22. On this form, there are clear lines which are horizontal and vertical. Over the horizontal line in the middle, folding is made upwards. A sweater is obtained in this way.

23. The sweater is reversed. Over the vertical line on it, folding is performed in a way to bring pieces on each other. A boat is obtained in this way.

24. Symmetrical parts are combined by folding over the diagonal making a 45-degree angle on the boat. In this way, a shoe is obtained.

25. A few steps will be made backwards for making pants. 25. The boat form is restored by opening the shoe format by one fold.

26. The sweater form is restored by opening the boat format by one fold. 

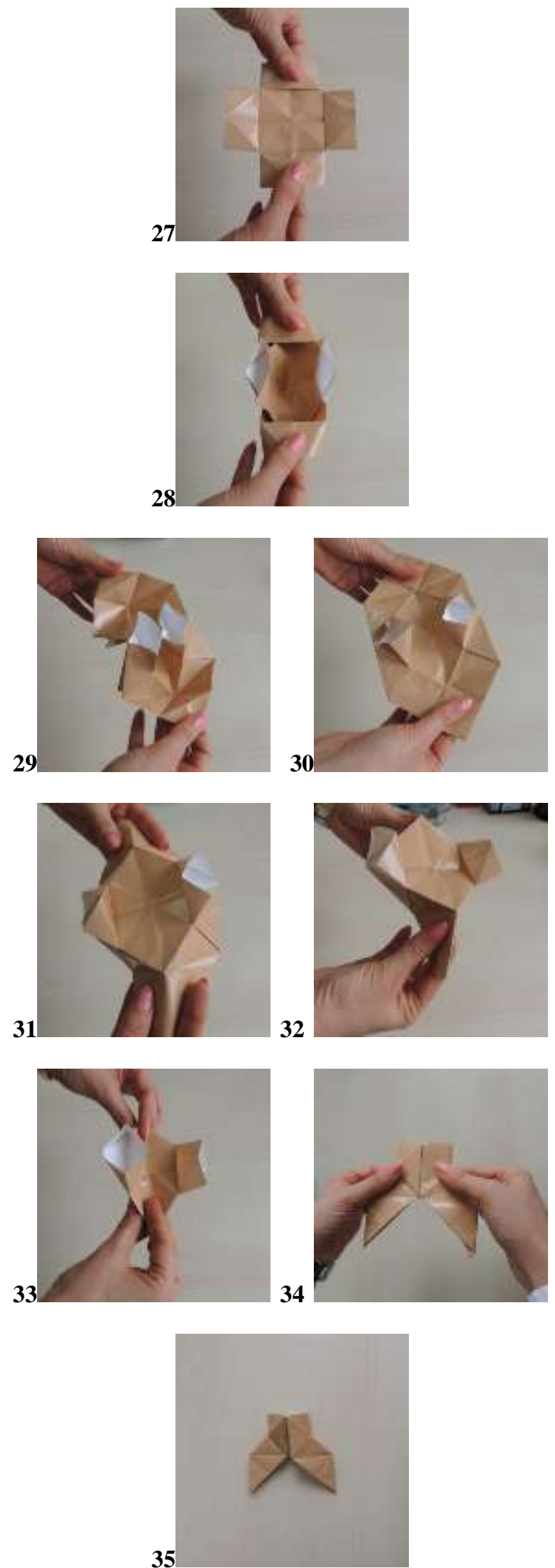

27. By going one step back from the sweater form, plus sign is reached.

28. In this way, two of the opposed rectangular pieces are held, one with right and the other with left hand.

29-30. With forefingers between the rectangular piece, middle fingers under it and thumbs on it, the paper is pulled simultaneously to both right and left. The paper is opened in this way.

31,32. On the opened paper, the pieces formed on the right and left sides are combined to obtain the lower part of the pants.

33,34,35. The other opposed rectangular pieces are also combined to form the waist of the pants. The pants are made in this way. 

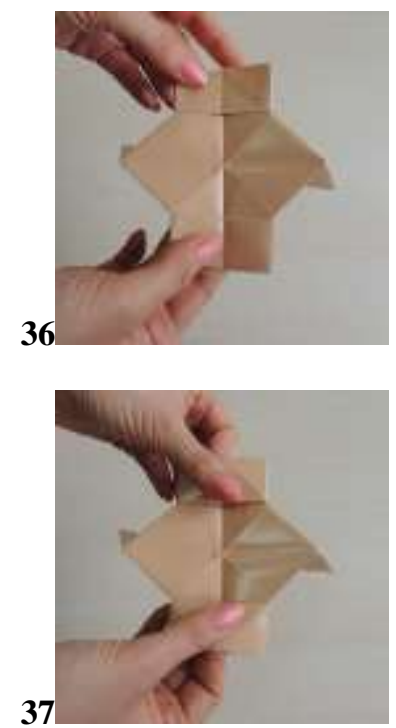

Feeling hungry, they enter a restaurant and sit at a table for two.
36. First, the waist of the pants is opened to both sides from top to bottom.

37. The rectangular pieces on the right and left sides are positioned in such a way as to keep the right rectangular piece with right hand and the left rectangular piece with left hand.

38. Forefingers are introduced into the rectangular piece, thumbs keep the top of the paper and middle fingers keep the bottom part of the paper for support.

39. While making the lower parts of the pants, the paper is opened by pulling to right and left in the same way as pulled from left and right.

40. On the opened paper, the pieces on the right and left sides are combined to make table legs.

41. All four parts are combined in this way to make the four legs and obtain the table. 
The bald guy's mother loves the food, calls for the waiter, and asks "Could you tell me the name of this lovely place?" The waiter replies "It is the

Star restaurant, madam."

On the way home, they visit a park and take a gondola to relax.

\section{When they finally} reach home, the bald guy's mother looks in her purse for keys.

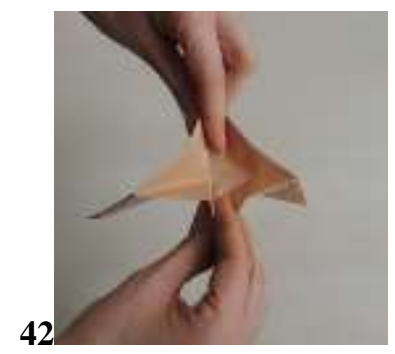

42. Holding the two legs of the table, folding is made over all eight lines on the top surface of the table.

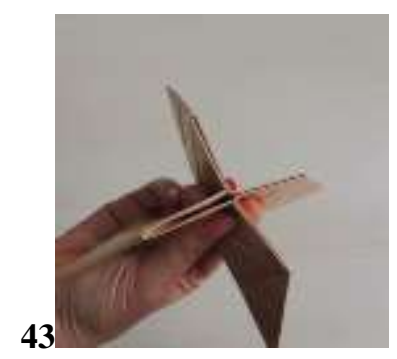

43. By combining the pieces in middle point of the square, a star shape is formed.

44. In the story the piece called "star" has four pieces. These four pieces are opened by combining every two of them.

45. When the paper is inverted, a gondola form is obtained.

46. The gondola is composed of two identical pieces. So, you can start from either of them. One part of the gondola is kept and the triangular piece contained in the other part is opened upwardly.

47. Make folding over the reference lines on the surface of the opened piece. Fold the opened triangle part outwards like an envelope. 

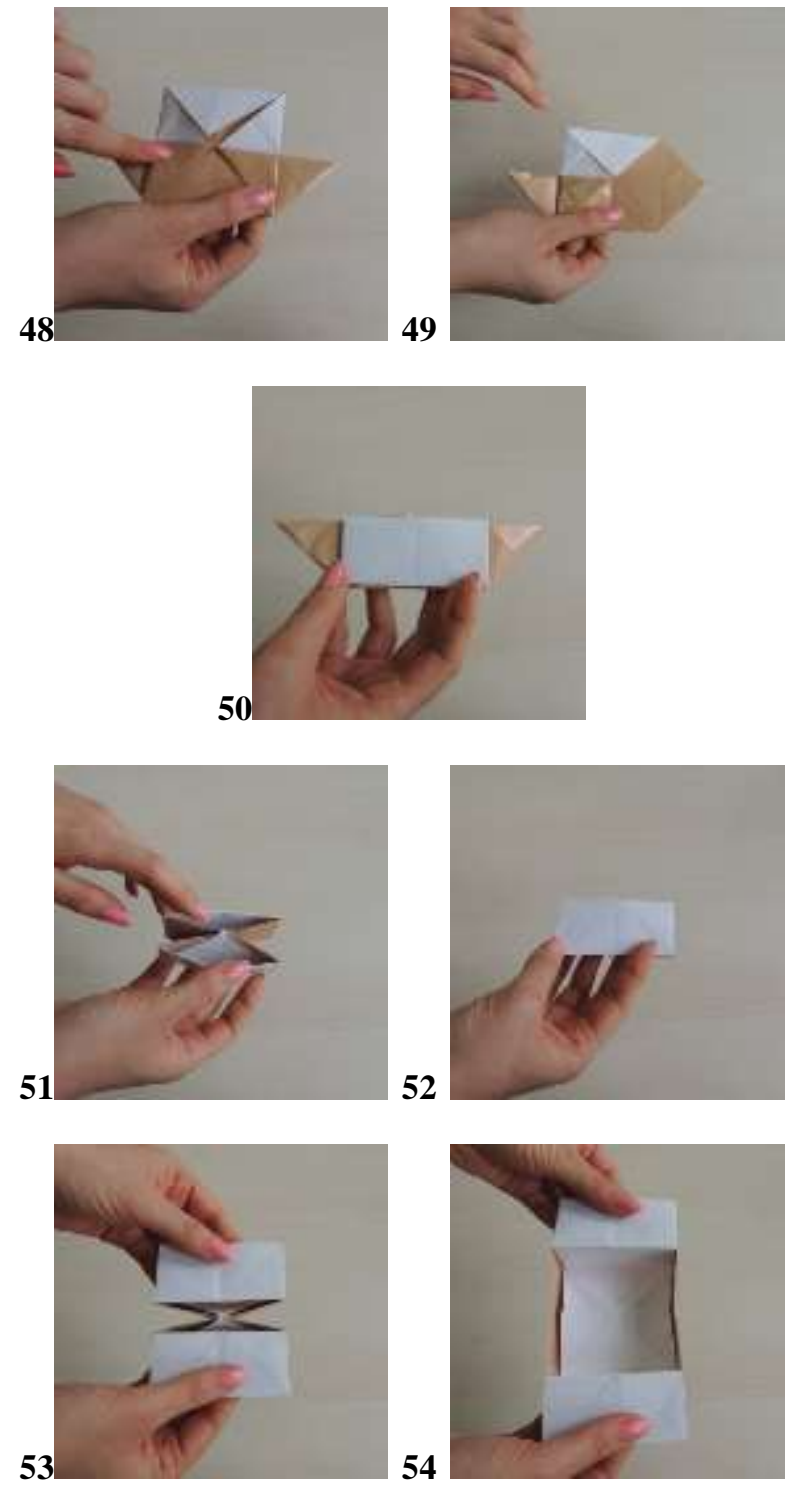

She opens the house door and they go in.
48,49. The pieces on the edge are also folded like an envelope by combining in the mid-point from the left and right side.

50. The rectangular piece is folded downwardly by lowering from top to bottom.

51,52. The process is repeated for the other piece of the gondola to obtain a bag.

$\mathbf{5 3 , 5 4}$. It is opened by pulling from the rectangular pieces on both edges of the bag.

55. A house is formed. It is shared how to use this product in the end of the process. It is also added that students can use this product as an individual trash box.

This work is licensed under a Creative Commons Attribution 3.0 License. 